\title{
Béla Bartók: invenção às avessas
}

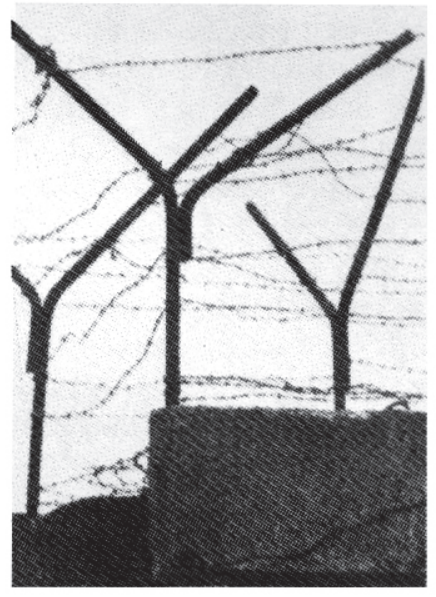

\author{
Júlio Medaglia
}

"Ele era pequeno e extremamente delicado. Sua bela e transparente expressão facial era calma e severa - dificilmente esboçava um sorriso. Tímido, falava baixo e deixava transparecer uma leve desconfiança constante. Frágil por natureza, sentia-se ferido ao presenciar a menor injustiça. $O$ olhar penetrante daquele corpo franzino, porem, qual pensador deliberadamente distante da movimentação cotidiana, deixava transparecer uma forte chama interior, plena de inquietação, que o impulsionava e o consumia." Nestas palavras se referiu a Béla Bartók um importante crítico musical de Nova York poucos dias após sua morte naquela cidade a 26 de novembro de 1945.

E não deixava de causar estranheza uma personalidade com tais características se transformar num herói desbravador, num ser com capacidade para dinamitar sistemas, virar idéias de ponta cabeça, de entortar o curso da história, numa figura-chave de um dos mais controvertidos momentos da trajetória humana, este século XX, apenas grafando meia dúzia de hieroglifos sonoros num papel. Mas foram exatamente os contrastes, os extremos radicais que pontuaram a vida e a obra de Béla Bartók. Se veio a falecer na capital "mercadológica" contemporânea, ele chegou ao mundo numa minúscula aldeia que sequer consta do mapa (na Hungria, então, e hoje Romênia); se teve diante de si toda riqueza do mundo nos últimos anos de sua existência naquela megalopole, dela, porém, não tirou proveito; e se optou por passar grande parte da vida convivendo com primitivos camponeses, em longínquas e isoladas aldeias, a música que produziu representaria parte importante do pensamento musical, da própria vida cultural deste século.

Avaliar-se a importância do trabalho de Béla Bartók em nossa era - pelo volume de sua biografia nas enciclopédias, pela beleza, "estranheza" ou presença constante de suas obras nas salas de concertos - não causaria um demasiado esforço. Para compreender-se, porém, a natureza de sua contribuição, necessita-se de um olho (e ouvido) clínico um pouco mais equipado e sensível. Isto porque Bartók levou às últimas conseqüências, e como nenhum outro, uma idéia por muitos esposada - e por alguns defendida com ardor - aquela que pretende transformar um bem cultural regional numa nova realidade, numa contribuição de estofo universal. A compreensão do trabalho e do método bartokiano tornar-se-ia ainda mais importante no Brasil, pois, mais do que qualquer país europeu, ele possui (possuía, melhor dizendo...) uma riquíssima cultura popular, fato este que motivou a proliferação dos chamados autores "nacionalistas", a maioria dos quais, porém, envoltos em equívocos culturais no mais das vezes impulsionados por não menores equívocos de natureza política. Como se sabe, a base da criação bartokiana assenta-se na utilização da matéria-prima folclórica de seu país (e circunvizinhanças) dando a ela um tratamento tecnológico com os recursos e equipamentos da antiga tradição composicional européia da música de concerto. $O$ fato em si não é novo. Todos nós sabemos ainda hoje como soa uma sarabanda, uma pavana ou uma bourrée graças à presença desses ritmos e maneirismos nas famosas suftes barrocas, e continua-
JÚLIO MEDAGLIA é maestro, compositor e autor de Música impopular (Editora Global). 


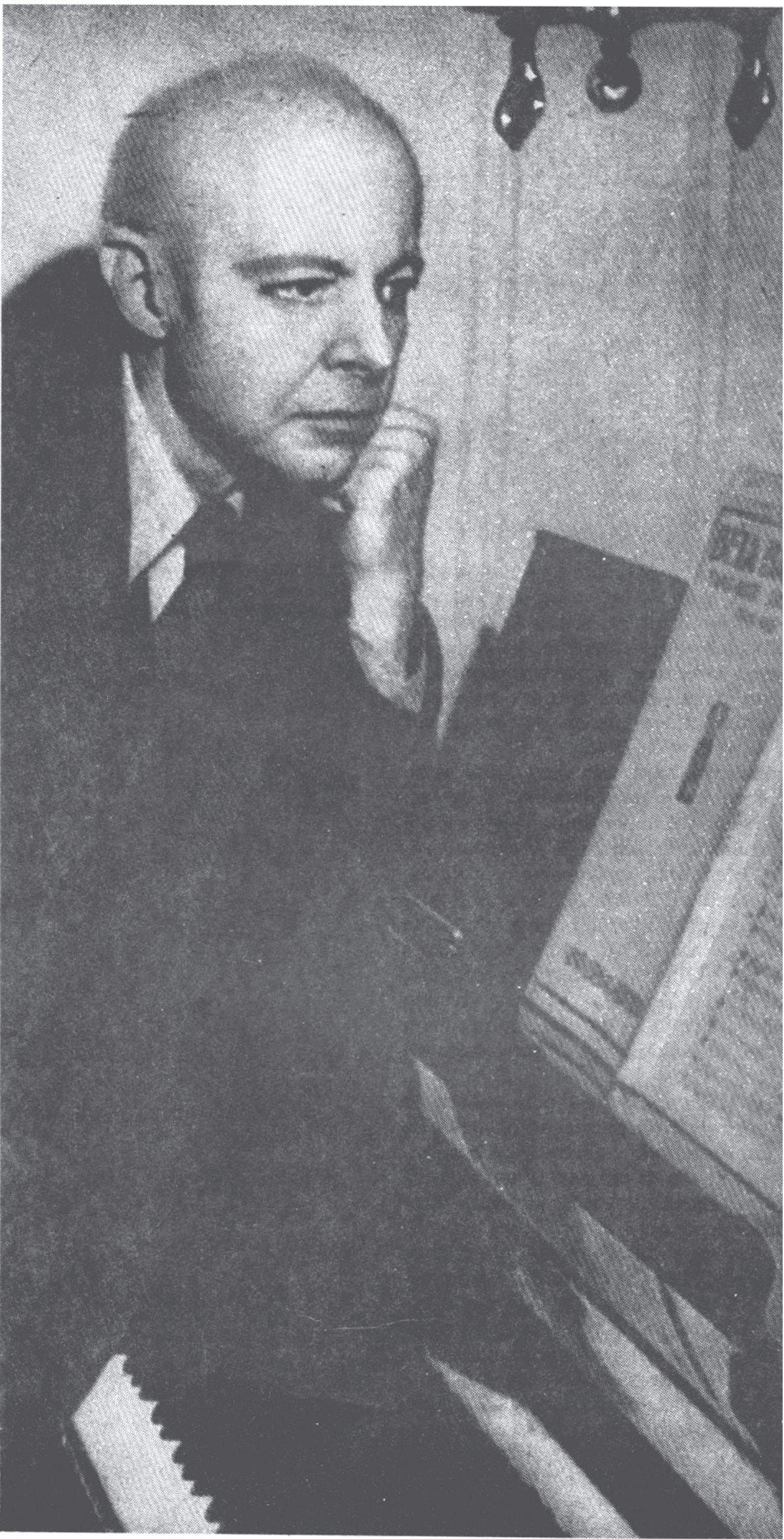

mos a ouvir sistematicamente minuetos pois essa dança de origem popular galgou a honrosa posição de "30 movimento" das mais famosas sinfonias clássicas. O minueto excitou-se e virou uma brilhante forma de dança popular em Viena, denominada valsa, não tardando assim a adentrar aos sofisticados salōes da pobreza austríaca - a mesma que financiou Salieri ou Mozart, Haydn ou Beethoven - ping-pong esse que gerou sofisticadas criações de Johann Strauss e também uma das mais elaboradas obras sinfônicas do século XX, "La Valse” de Ravel. A vitalidade e o "descomprometimento" da cultura popular a excitar o autor "erudito" não é, portanto, algo de novo. O approach, porém, da cultura popular por parte do músico clássico é que sempre foi "de cima para baixo", isto é, ele apropriava-se de um fenômeno cultural espontâneo, na maioria das vezes anônimo e o transformava, a seu bel-prazer, num elemento quase exótico da sala de concerto, sendo que o tratamento tinha mais a ver com seus proprios maneirismos composicionais do que com as características da matéria-prima requisitada. Debussy chegou a dizer que "se um pobre camponês fosse convidado para assistir uma composição sinfônica baseada em um de seus ingênuos cantos de colheita, ao presenciar as triturações sinfônicas e contrapontísticas realizadas com sua simples canção, teria tudo para esquecer sua regiāo de origem...". E, mais adiante: “...ouvi mais uma peripécia sinfônica do sr. Rimsky-Korsakov repleta de "folclore original", cujo resultado mais parecia posters de publicidade turística de Cook \& Son do que uma manifestação cultural...".

Ironias à parte, poderia-se dizer que raramente um fenômeno de origem popular levado ao sacrossanto palco do concerto trouxe consigo características estruturais profundas, dele utilizando-se, no mais das vezes, apenas um ou outro componente, um elemento rítmico ou uma frase melódica. Pior do que isso foi um fato que ocorreu neste século quando essa transferência de local e status de um fenômeno cultural popular tinha por base uma ação polf́tica. Os estetas do "realismo socialista" comandados por Sdanov acreditavam que "toda arte emana do povo", que o camponês deveria freqüentar e sair da sala de concertos assoviando a melodia ouvida, e todos estavam seguros de que a presença de uma expressão telúrica em meio às guirlandas de uma sala de concertos em noite de gala conferiria àquele despojado fenômeno uma ascensão social ou um "reconhecimento cultural". Algo como se se colocasse um pedaço

$\begin{array}{lllllll}R & E & V & \text { I } & S & T & A\end{array}$

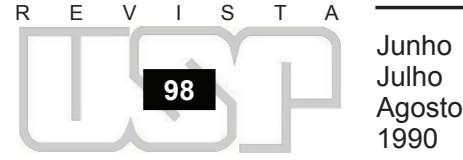

Junho

Agosto 1990 
de pé-de-moleque numa jarra de cristal e ele assumisse o sabor e a aura das coisas nobres...

O raciocínio de Bartók foi outro. Ele não pretendeu fazer "média" com a cultura popular e nem dela lançar mão quando sua musa the negasse inspiração. Estabeleceu, isto sim, um compromisso cultural efetivo com as mais diversas formas de expressão que conhecera já em sua adolescência, pois acreditava que nelas havia embutidos componentes em condições de subverter um sem-número de conceitos da chamada "cultura superior" européia.

E a primeira grande surpresa apresentada por Bartók à vida musical de seu país e, logo em seguida, internacionalmente, era a de que a "mais autêntica" e rica música húngara nada tinha a ver com os virtuoses violinos e xilofones da música cigana. Isso vinha até mesmo questionar um dado de há muito estabelecido, já que autores do mais elevado conceito como Liszt ou Brahms compuseram dezenas de "danças húngaras" baseadas no brilho exibicionista e dançante da expressão cigana. Inicialmente foi difícil a Bartók e seu colega de pesquisa, o compositor Zoltan Kodaly, provar a todos que as jovens das distantes e isoladas aldeias cantavam outro tipo de canções enquanto colhiam a uva, tanto quanto seus pais ao amassá-las com os pés na preparação do vinho. Lançando mão dos primeiros recursos de captação sonora criados por Thomas Edson, esses dois jovens músicos húngaros preencheram mais de 16.000 rolos de cera com gravações realizadas nos mais longínquos e ignorados rincões da Hungria e dos Bálcãs em geral. $\mathrm{E}$ a audição desse material de pesquisa representou para Bartók e Kodaly um verdadeiro "alívio", pois através do convívio com aquelas formas de expressão musical, eles puderam se "dar conta" que é possível compor distante do mundo tonal - do "dó maior ou fá sustenido menor" - que há centenas de anos formava o chão acústico da música ocidental, tanto quanto seus ritmos regulares e suas melodias simétricas - todas em oito compassos.

Bartók nasceu em Nagyszetmiklós a 25 de março de 1881 . Nessa pequena aldeia seu pai era diretor de uma escola de agricultura, o que the facilitou o contato com a música folclórica campesina e não contaninada com os ciganismos da expressão urbana. Sua mãe era professora primária e também razoável pianista amadora, responsável pelos primeiros contatos do menino Béla com a música elaborada. Tanto quanto Liszt, o outro "monstro sagrado" da música húngara, Bartók foi menino prodígio. Já aos
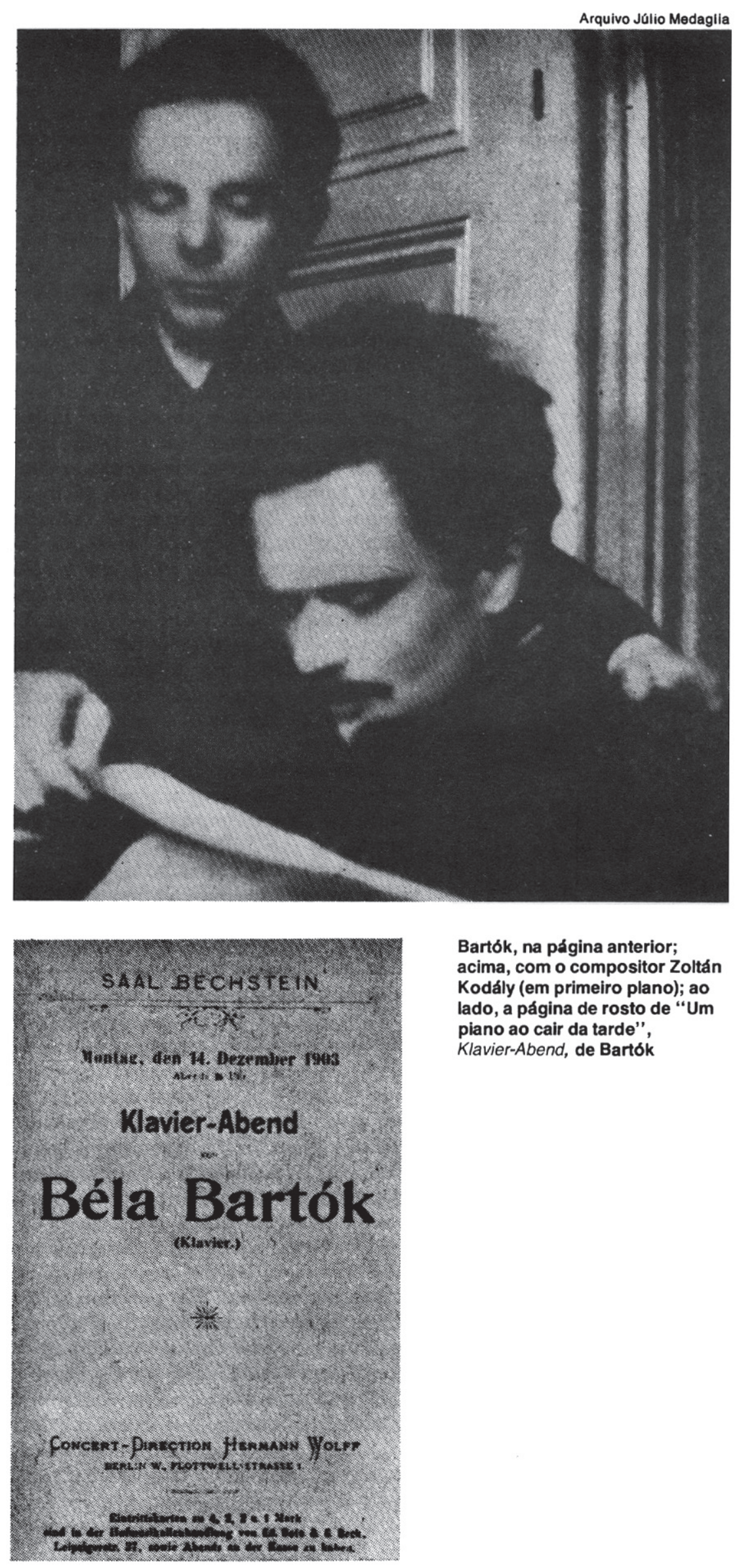

Bartók, na página anterior; acima, com o compositor Zoltán Kodály (em primeiro plano); ao lado, a página de rosto de "Um piano ao cair da tarde", Klavier-Abend, de Bartók 
10 anos causava furor como pianista ao mesmo tempo que arriscava suas primeiras composições. Jovem ainda mudou-se para uma cidade maior (Pressburg) e aos 18 anos em Budapeste matricula-se no Conservatório Franz Liszt. Aí adquire sólidos conhecimentos históricos, sobretudo da tradição centro-européia (Beethoveı/Brahms/Wagner) e suas primeiras composições do período nela se baseiam. Durante muito tempo, porém, Bartók aprofunda seus conhecimentos teóricos e pianísticos deixando de lado a atividade composicional.

"Como um inesperado e estrondoso raio um acontecimento rompeu de uma só vez com minha estagnação: a première em Budapeste do poema sinfônico Assim falou Zoroastro (Also sprach Zaratustra) de Richard Strauss em 1902. Aquela obra que havia espantado os músicos e o público da cidade despertou em mim um enorme entusiasmo para a composição", dizia ele numa autobiografia publicada em 21. Mas do ponto de vista estilístico um outro fato da maior relevância viria a ocorrer logo em seguida, mesmo já tendo inúmeras de suas composições executadas - inclusive sua rapsódia para piano e orquestra Op. 1: seu contato com Claude Debussy. Assim como o encontro deste grande músico francês com Erik Satie proporcionou ao seu trabalho um efeito desinibidor, ao avistar-se com Debussy e absorver suas idéias, Bartók libertou-se de entraves vários, assumindo de estalo sua própria personalidade sonora. Assim como Debussy havia rompido com uma sólida e extensa estrutura formal que se impunha até seu tempo, Béla Bartók livremente reencontra-se com aqueles valores tão inusitados que a gente simples de seu país havia lhe apontado. Neste momento ele apressa-se em completar sua busca, pois temia que a aceleração do processo industrial acabaria por destruir as velhas práticas de produção artesanais, calando a voz das fiandeiras e estirpando de suas vidas o hábito de cantar. A chegada de modernos meios de transporte ao interior traria consigo igualmente toda uma desordenada informação sonora que, com a maior facilidade, iria mesclar-se e dilapidar a expressividade despojada do camponês. Não se sabe o que teria causado maior espanto aos habitantes da aldeia, se as novas máquinas de tear ou os engenhosos aparelhos de gravação com seus enormes tubos metálicos onde o assustado camponês deveria entoar suas canções.

Este rastreamento cultural chegou a estender-se além das fronteiras de seu país, razão pela qual Bartók chegou a ser criticado, da mesma forma quando se recusou a escrever panfletos sonoros num momento de divergências geopolíticas entre a Hungria e a Romênia.

Um meticuloso trabalho de filtragem e aproveitamento daqueles materiais - melodias e ritmos assimétricos, harmonizações não-tonais, timbres instrumentais estranhos ao "culto" ouvido ocidental - foi edificando, com o tempo, uma sui generis linguagem composicional. Algumas vezes a própria matéria-prima se metabolizava numa nova e elaborada realidade composicional e outras o seu desejo de alçar vôos livres com base naquela vasta motivação o levava à construção de um folclore imaginário.

Essa sua música com a força da terra era uma provocação ou uma resposta ao não menos bárbaro Igor Stravinsky com sua Petrusca e Sagração. Enganaram-se, porém, aqueles que acharam ser esse o som do caos. Meticuloso por natureza, cientista na forma de tratar o objeto encontrado, Bartók trazia consigo impreterivelmente um metrônomo, como um matemático convive com sua régua de cálculo. Suas obras são cronometradas à precisão de segundos. Chegou ao ponto de elaborar um evangelho segundo Béla Bartók da música de nosso tempo, as 153 progressivas peças para piano do seci Microcosmos, afim de que os nascidos neste século adentrassem lentamente nos mistérios da invenção sonora moderna.

Como todo aquele que subverteu a ordem dos acontecimentos naquela primeira metade de século, Bartók trombou com os diversos tipos de fascismo que se instalaram no continente europeu. Ele precisou se esconder por diversas vezes e em diversos países, chegando, por fim, a abandonar o seu próprio continente de origem, refugiando-se na América do Norte. Bartók participou de toda a movimentação revolucionária da música na primeira metade deste século, atuando polemicamente em todos os continentes.

Desgraçadamente, porém, encerrou seus dias pouco tempo antes de ver sua criação reconhecida internacionalmente e ganhar a posição de obrigatoriedade no repertório de todos aqueles que se dedicam à atividade musical. Desgraçadamente, pois, em seu bolso, naquele momento, não foram encontrados sequer os mínimos tostões necessários para o custeio de suas exéquias.

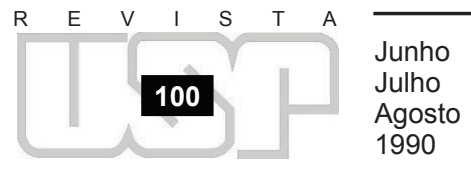

